\title{
HOMEOSTATIC ARK AS THE MAIN MEANS IN THE STRATEGY OF SPACE EXPLORATION
}

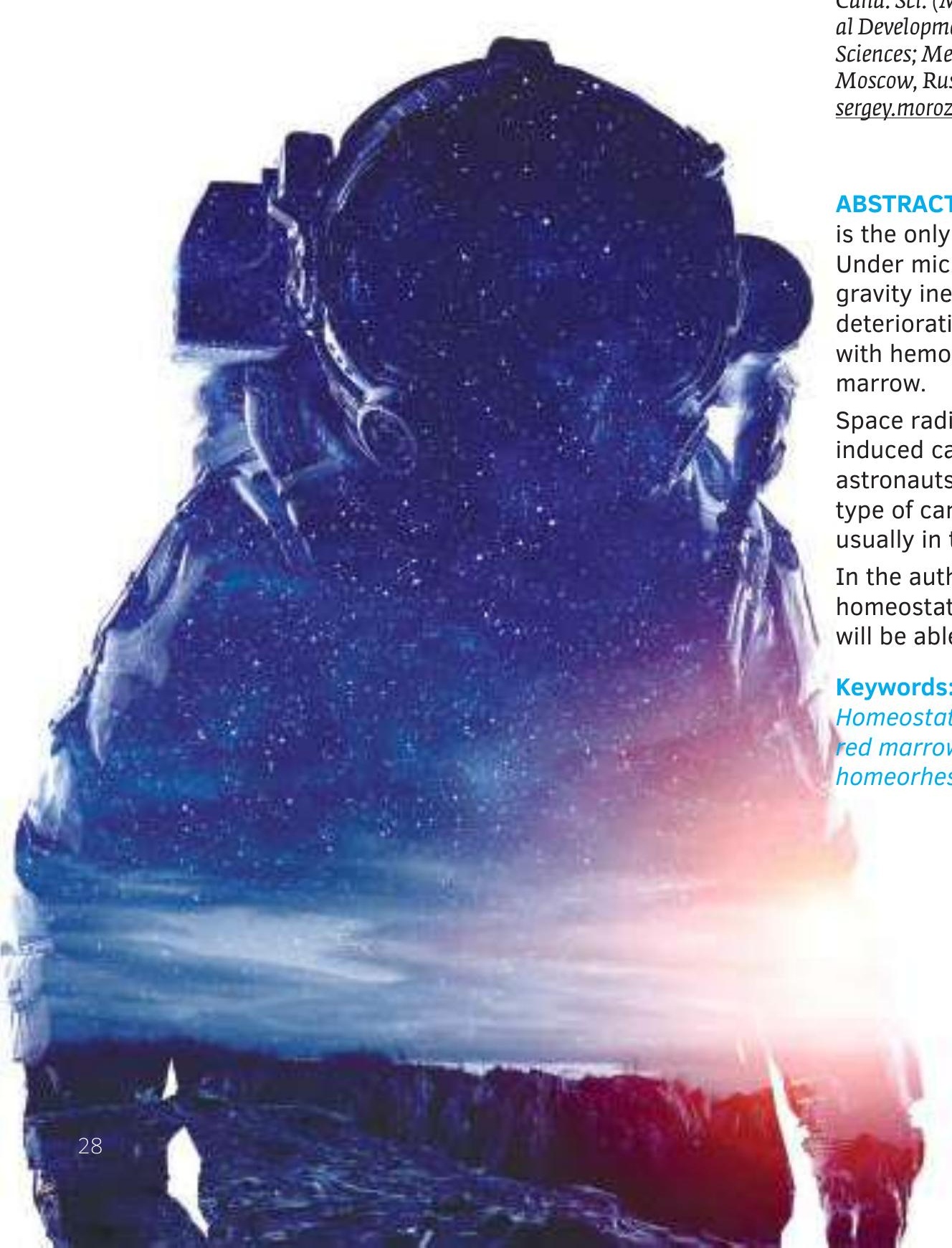

Sergey L. MOROZOV,

Cand. Sci. (Medicine), Leading research fellow, National Development Institute of the Russian Academy of Sciences; Member of the First Parliament of Asgardia, Moscow, Russia,

sergey.morozov@asgardia.space

ABSTRACT I In human phylogenesis gravity is the only and absolute skeletogenous factor. Under microgravity conditions the absence of gravity inevitably leads to the bony skeleton deterioration that is in no way compatible with hemopoiesis processes in the red bone marrow.

Space radiation is the root cause of radiationinduced cancer listed in the passional of astronauts, cosmonauts and candidates. Such type of cancer appears twice more often than usually in the same age groups.

In the author's opinion only providing homeostatic arks are engineered humankind

Keywords: homeostatic ark, International Homeostatic Ark (IHA), microgravity, red marrow critical mass, hypoxia, hypoxemia, homeorhesis 


\section{ГОМЕОСТАТИЧЕСКИЙ КОВЧЕГ КАК ГЛАВНОЕ СРЕДСТВО}

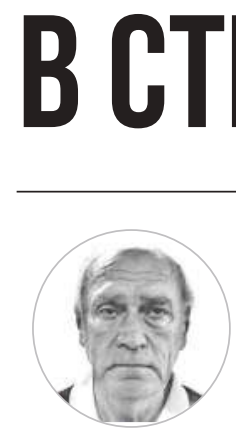

PATEГ

Сергей Львович МОРОзОВ, кандидат медищинских наук, ведущий научный сотрудник Национального института развития РАН, член первого парламента Асгардии, Москва, Poccus,

sergey.morozov@asgardia.space

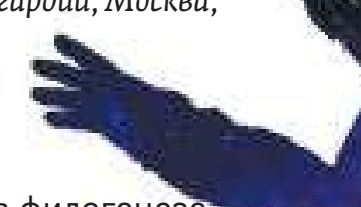

АНнОТАЦИЯ I Сила тяжести в филогенезе человека является единственным и абсолютным скелетообразующим фактором. Ее отсутствие в условиях микрогравитации неизбежно ведет к деградации костного скелета, и это совершенно несовместимо с процессами кроветворения в красном костном мозге.

Космическая радиация - первопричина радиационно-индуцированных раковых образований организма, перечисленных в мартирологе астронавтов, космонавтов и кандидатов. Частота их возникновения примерно в два раза выше среднестатистической в аналогичных возрастных группах.

По мнению автора, человечество сможет заселить весь космос, только создав гомеостатические ковчеги.

Ключевые слова: гомеостатический ковчег, Международный гомеостатический ковчег (МГК), микрогравитация, критическая масса красного костного мозга, гипоксия, гипоксемия, гомеорез 


\section{НЕОБХОДИМЫЕ УСЛОВИЯ КОСМИЧЕСКОЙ ЭКСПАНСИИ}

Сила тяжести в филогенезе человека является единственным и абсолютным скелетообразующим фактором. Ее отсутствие в условиях микрогравитации (невесомости) ведет к деградации костного скелета, и это совершенно несовместимо с процессами кроветворения в красНом костном мозге.

У новорожденных в условиях микрогравитации, в их онтогенезе (сокращенном повторении филогенеза, то есть в процессе развития индивидуального организма от оплодотворения (при половом размножении) или от момента отделения от материнской особи (при бесполом размножении) до конца жизни, в отличие от его исторического филогенеза) никогда не сформируется нормальный скелет. Родившись вне условий гравитации Земли, они не смогут жить на поверхности Земли в условиях ее нормальной гравитации (1 g). У таких новорожденных будут слабые хрящевые скелеты своеобразных "рыб космоса" - то есть тотальный рахит с резким замедлением активности точек окостенения. Если они попадут обратно на Землю, гравитация Земли раздавит их, как рыб, выловленных с большой глубины.

Фримен Дайсон (Freeman John Dyson) в своих научных работах никак не учитывает фактора гравитации. Он предлагает отправить для колонизации новых планет не людей, а их эмбрионы вместе с роботоняней. Таким же образом, по его мнению, можно транспортировать все живые организмы - от бактерий до животных (проект «Ноев ковчег» [1]).

При этом адаптация организма человека к жесткой космической радиации в принципе невозможна. Она разрушает процесс генерации эритроцитов, нарушает синтез гемоглобина. Поэтому клетки организма начинают испытывать гипоксию (недостаток кислорода) от гипоксемии, и человек погибает при нарастающих симптомах удушья .

Клинически это выглядит как «беспричинная» мгновенная смерть от остановки сердца. Согласно приводимому ниже мартирологу астронавтов, космонавтов и кандидатов, причиной смерти 28 человек являлась именно острая сердечная недостаточность, и еще 15 человек погибли от последствий инсульта и инфаркта миокарда, которые развились на фоне постепенно нарастающей гипоксии от гипоксемии.

От гипоксии по причине гипоксемии погибло 43 человека (почти столько же, сколько погибло от рака - 44 человека). Это две основные, равновесные (по 20\% на каждую) причины смерти от воздействия факторов космического полета на человека.

Жесткая космическая радиация, как один из ведущих факторов космического полета (наряду с микрогравитацией), подавляет всю иммунную систему организма, синтез лейкоцитов и тромбоцитов, плазматических клеток, работу лимфоузлов, лимфоидной ткани, селезенки и коры надпочечников.

Космическая радиация является первопричиной радиационно-индуцированных раковых образований, перечисленных в мартирологе астронавтов, космонавтов и кандидатов. Частота их возникновения не менее чем в два раза выше среднестатистической в аналогичных возрастных группах.

По мнению автора, человечество сможет заселить весь космос, только создав гомеостатические ковчеги. Вне этих ковчегов существовать в космосе оно не сможет.

Идеи Илона Маска, Баса Лансдорпа и Денниса Тито о прямом заселении планет Солнечной системы вряд ли окажутся состоятельными с точки зрения современной теории космической медицины.

Из-за существенно меньшей силы тяжести на поверхности Марса, даже при достаточном запасе кислорода, привезенного с Земли, марсонавты-космонавты-астронавты начнут погибать уже к концу первого года от недостатка кислорода в крови (от гипоксемии). Для освоения планет Солнечной системы необходимо создание гомеостатического ковчега, в котором поддерживается гомеорез онтогенеза человека, с постоянной искусственной гравитацией около $1 \mathrm{~g}$.

На сегодняшний день в мире нет никакой альтернативы международному проектированию и строительству всем миром гомеостатического ковчега (МГК) вместо отжившей свой век MKC [2, 3].

\section{І. ПОЧЕМУ НЕОБХОДИМА ИСКУССТВЕННАЯ ГРАВИТАЦИЯ?}

Кроветворная система - система органов, отвечающих за постоянство состава крови. Основной функцией кроветворных органов является постоянное пополнение клеточных элементов крови - кроветворение, или гемопоэз (лат. haemopoiesis).

Основными компонентами кроветворной системы являются костный мозг, лимфатические узлы и селезенка. В костном мозге происходит образование эритроцитов, разных форм лей- 
коцитов и тромбоцитов. Лимфатические узлы участвуют в процессах кроветворения, вырабатывая лимфоциты, плазматические клетки. Селезенка состоит из красной и белой пульпы [4]. Продолжительность жизни эритроцитов у человека составляет 100-120 дней. Эритроциты содержат гемоглобин, который переносит кислород ко всем клеткам и тканям организма.

Эритроциты образуются интраваскулярно (внутри сосудов) в синусах красного костного мозга. На долю кроветворной части скелета приходится $45 \%$ массы скелета и до 7\% массы тела.

Процесс освоения суши животными, вышедшими из воды, привел к развитию у них особого феномена - красного костного мозга - как прямого следствия силы тяжести, действующей на сухопутных существ на поверхности Земли.

Поэтому снижение уровня силы тяжести, возникающее в определенных фазах космических путешествий, приводит к деградации красного костного мозга и нарушениям процессов кроветворения.

Критическая масса потери костной части скелета, на основе эмпирических данных, составляет около $15 \%$. Этот показатель ограничивает пребывание человека в состоянии микрогравитации (которая имеет место в невесомости на борту ИСЗ, в частности на MKC).

Каждый человек имеет строго индивидуальные возможности регенерации кроветворной части скелета. Шесть месяцев, проведенные космонавтами в условиях невесомости на борту космической станции "Мир", привели к потере массы губчатой кости в дистальном отделе голени от $2 \%$ до $24 \%$.

Спустя 4-6 месяцев космического полета минеральная плотность костей астронавтов-космонавтов уменьшается настолько, что по возвращении на Землю у них нередко возникают спонтанные переломы костей скелета при обычных земных нагрузках. Кости теряют кальций неравномерно. Больше всего он вымывается из участков кости, которые формируют суставы. Также замедляется процесс ремоделирования постоянного обновления костной ткани.

Сердечно-сосудистая система - самая гравитационно-чувствительная система в организме человека, она рассчитана на стабильную работу исключительно в условиях постоянной силы тяжести. Отсутствие гравитации приводит к уменьшению объема крови, мягкости вен, ослабленным барорецепторным рефлексам и сниженной ортостатической устойчивости организма. Опаснее всего для человека быстрое развитие атрофии сердечной мышцы и общая анемия кроветворной системы.
Обследования космонавтов во время космических полетов длительностью в несколько месяцев показали, что они могут терять в среднем 0,5-1\% красной костной массы каждый месяц, даже если продолжают тренироваться. А это означает, что критическая граница для возможности восстановления потери красной костной части скелета составляет не более 15 месяцев непрерывного нахождения в условиях микрогравитации. Если человек по каким-либо причинам превысит эту критическую границу, то при возвращении на Землю он либо погибнет, либо останется инвалидом.

Космонавт Валерий Поляков (Valeri Polyakov) единственный человек в мире, находившийся на станции "Мир» более 14 месяцев (437 суток - 14,56 месяца) [5]. Он экспериментально де-факто достиг критического состояния подавления кроветворной функции своего скелета в условиях микрогравитации.

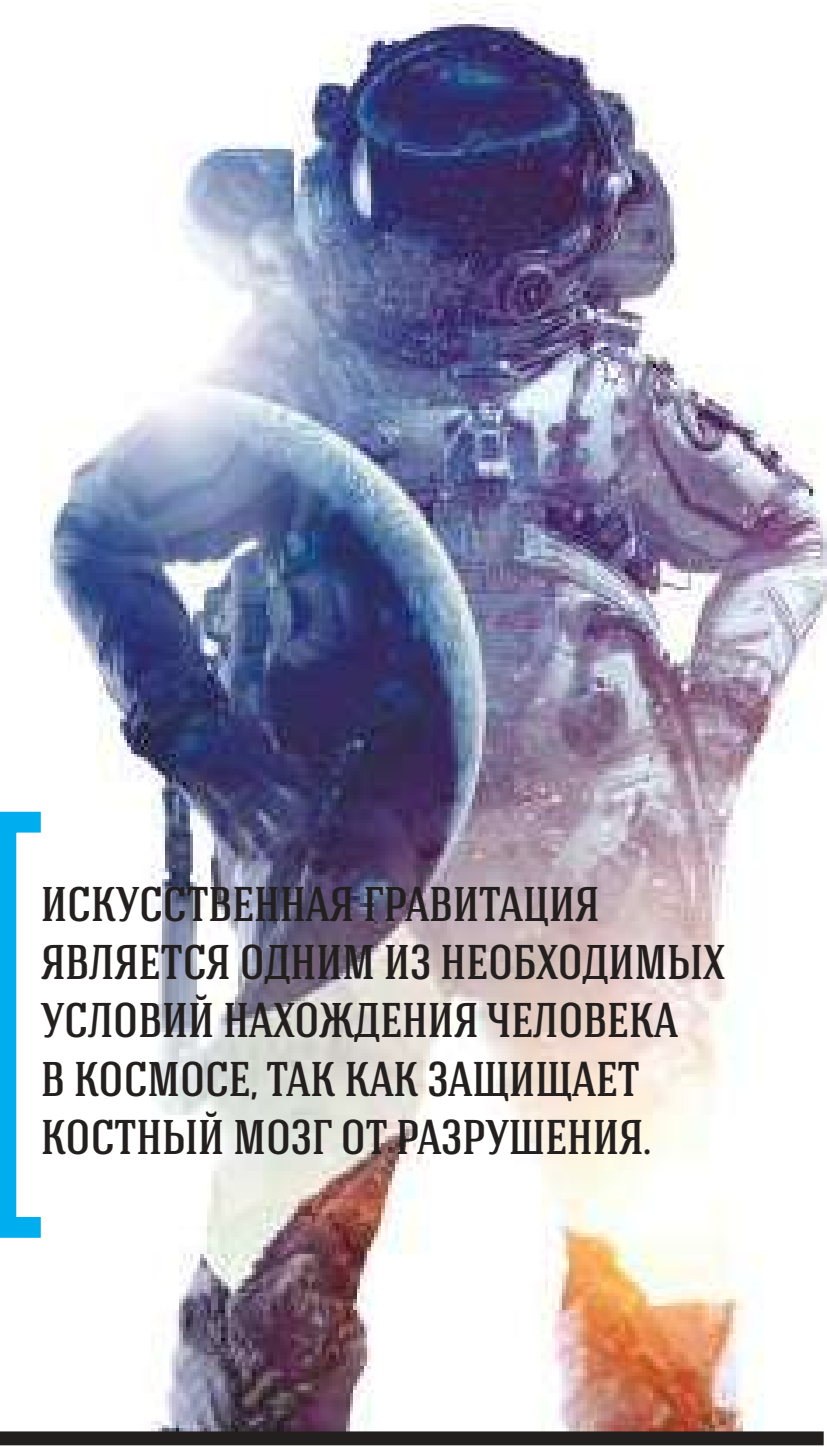


Не представляются реальными проекты Денниса Тито (Dennis Tito) (Inspiration Mars Foundation) и Баса Лансдорпа (Bas Lansdorp) (Mars One), никак не учитывающих этот критический фактор. Вряд ли Илону Маску удастся заселить Марс миллионом переселенцев с Земли.

Сила тяжести на марсе составляет около $40 \%(0,378$ g) от уровня силы тяжести на Земле (на Луне сила тяжести составляет около 16,5\% $(0,165$ g)). Костная ткань у переселенцев на Марсе постепенно уменьшится примерно в этой же пропорции $(100 \%-40 \%=60 \%)$, и станет меньше критической потери в пересчете на долю красного костного мозга примерно в два раза $(\{60 * 0,45\} / 15=1,8)$. Соответственно, у переселенцев на Луне костная масса станет на примерно $84,5 \%(100 \%-16,5 \%=84,5 \%)$ меньше, то есть примерно в два с половиной раза меньше критической массы в пересчете на массу красного костного мозга $(\{84,5 * 0,45\} / 15=2,535)$.

Вещество красного костного мозга может функционировать на критическом уровне потери своей массы не более чем 7,5-15\% (размеры индивидуального разброса) от общего его количества. Далее разовьется нарастающая гипоксемия. Примерно такую критическую массу красного костного мозга переселенцы потеряют только за время перелета к Марсу (период реальных перелетов сегодня составляет от 128 до 333 дней), если весь этот перелет будет происходить в условиях микрогравитации.

Из-за существенно меньшей силы тяжести на поверхности Марса, даже при достаточном запасе кислорода, привезенного с Земли, марсонавты-космонавты-астронавты начнут погибать уже к концу первого года от недостатка кислорода в крови. А на полет туда и обратно понадобится не менее 33 месяцев [6], что примерно в два раза превышает теоретически рассчитанный критический уровень в 450 суток нахождения человека в условиях микрогравитации.

Исходя из этого, человечество сможет жить только на постоянных орбитах вокруг этих планет и их спутников в гомеостатических ковчегах с постоянной искусственной гравитацией, и кратковременно периодически посещать расположенные на их поверхности и в недрах важные промышленные производства, которые будут постоянно обслуживаться исключительно роботами $[7,8,9,10,11,12,13,14,15]$.

Для освоения планет Солнечной системы необходимо создание гомеостатического ковчега, в котором поддерживается гомеорез онтогенеза человека (поддержание постоянства в развивающихся системах на основе диалектического взаимодействия положительной и отрицатель- ной обратной связи) $[16,17]$, с постоянной искусственной гравитацией около $1 \mathrm{~g}$.

У обитателей гомеостатического ковчега должен поддерживаться гомеостаз всех биологических и физиологических показателей организма, точно такой же, какой имел место на Земле.

На таком обитаемом гомеостатическом ковчеге должна быть установлена мощная как (пассивная) механическая, так и (активная) автоматическая электромагнитная защита (экран) от ионизирующего космического излучения, которое также несовместимо с работой органов кроветворения.

В чем в данном предложении заключена научная новизна? Первые научные проекты космических поселений людей выдвинули К. Циолковский [18] и Ф. Цандер [19]. Перечисление этих проектов - отдельная историческая тема. Наши интересы лежат в технологической плоскости принципиально новой компоновки космических платформ, предназначенных для постоянного проживания людей в космосе. Это должна быть концептуальная технологическая замена современных станций временного посещения (СВП) типа «Мир» и МКС на станции-корабли постоянного проживания (СПП).

\section{Предлагаемые СПП должны иметь следующие харак- теристики:}

1) постоянную искусственную гравитацию примерно в $1 \mathrm{~g}$, что позволит не ограничивать максимальный критический срок пребывания в космосе приблизительно 15 месяцами (около 450 дней);

2) массивную свинцовую защиту жилых отсеков, снижающую уровень космического облучения в 350-500 раз, тем самым приближая интенсивность воздействия к уровню космической радиации на поверхности Земли на уровне моря; а также экзоскафандры с полной защитой от космического излучения при неограниченной по времени работе в открытом космосе;

3) атомную энергетическую установку в дополнение к солнечным батареям;

4) атомные двигатели в дополнение к традиционным;

5) СПП должны стать космическими городами-кораблями с полным регенерационным циклом;

6) СПП будут продолжительное время собираться на орбите Земли, поэтому данный проект требует больших затрат и, следовательно, должен стать международным. Это должны быть настоящие индустриальные "космические верфи» («производство средств производства»). 


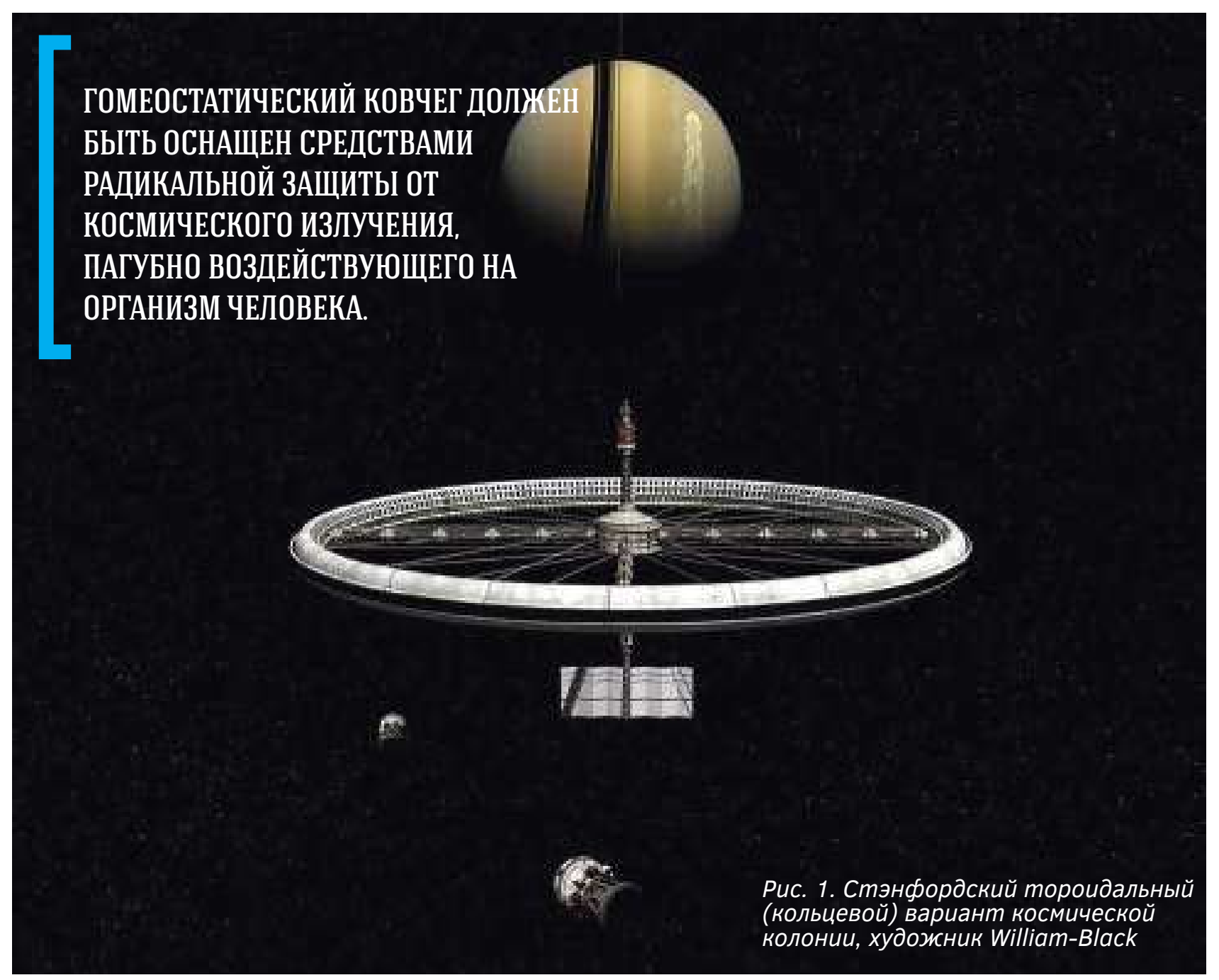

\section{II. ПОЧЕМУ НЕОБХОДИМА ПОЛНАЯ}

\section{ЗАЩИТА ОТ КОСМИЧЕСКОГО ИЗЛУЧЕНИЯ?}

В отсутствие атмосферного слоя, защищающего людей на Земле, космонавты на МКС подвергаются более чем 350-кратному интенсивному космическому облучению. За сутки члены экипажа получают дозу радиации примерно равнозначную облучению человека на Земле за год (в размере около 0,3, 0,8 или 1,0 миллизиверта (м3в)) [20].

За стандартные 180 суток полета космонавт набирает от 50 до 150 мЗв. Это сумма облучения, которую получит человек, если будет делать рентген 150-400 раз за полгода (что эквивалентно одному-двум рентгеновским обследованиям ежедневно). После 40 рентгеновских обследований риск заболеть раком легких, по статистике, возрастает на 50-70\% (а после 400 рентгеновских обследований (67 раз в месяц) этот риск увеличивается в 5-7 раз).

Всего за 60 лет [21] (с 26 июля 1958 года по 23 апреля 2018 года) в мире скончалось от прямых онкологических заболеваний 44 космонавта-астронавта и кандидата на полет в космос (из них 20, или 45,45\%,- из России), 28 умерли от острой сердечной недостаточности, 15 погибли от инсульта (а также инфаркта миокарда) и его (их) последствий, что составило в общей сумме 87 человек $(43+44=87)$, или $40,1 \%$ от общего числа из 217 умерших (из них 107 , или 49,3\% от общего количества, - из России). В среднем в России в обычных группах населения этот показатель более чем в два раза ниже и равен 16,6\% [22]. 


\section{АСТРОНАВТ-ЖЕНЩИНА}

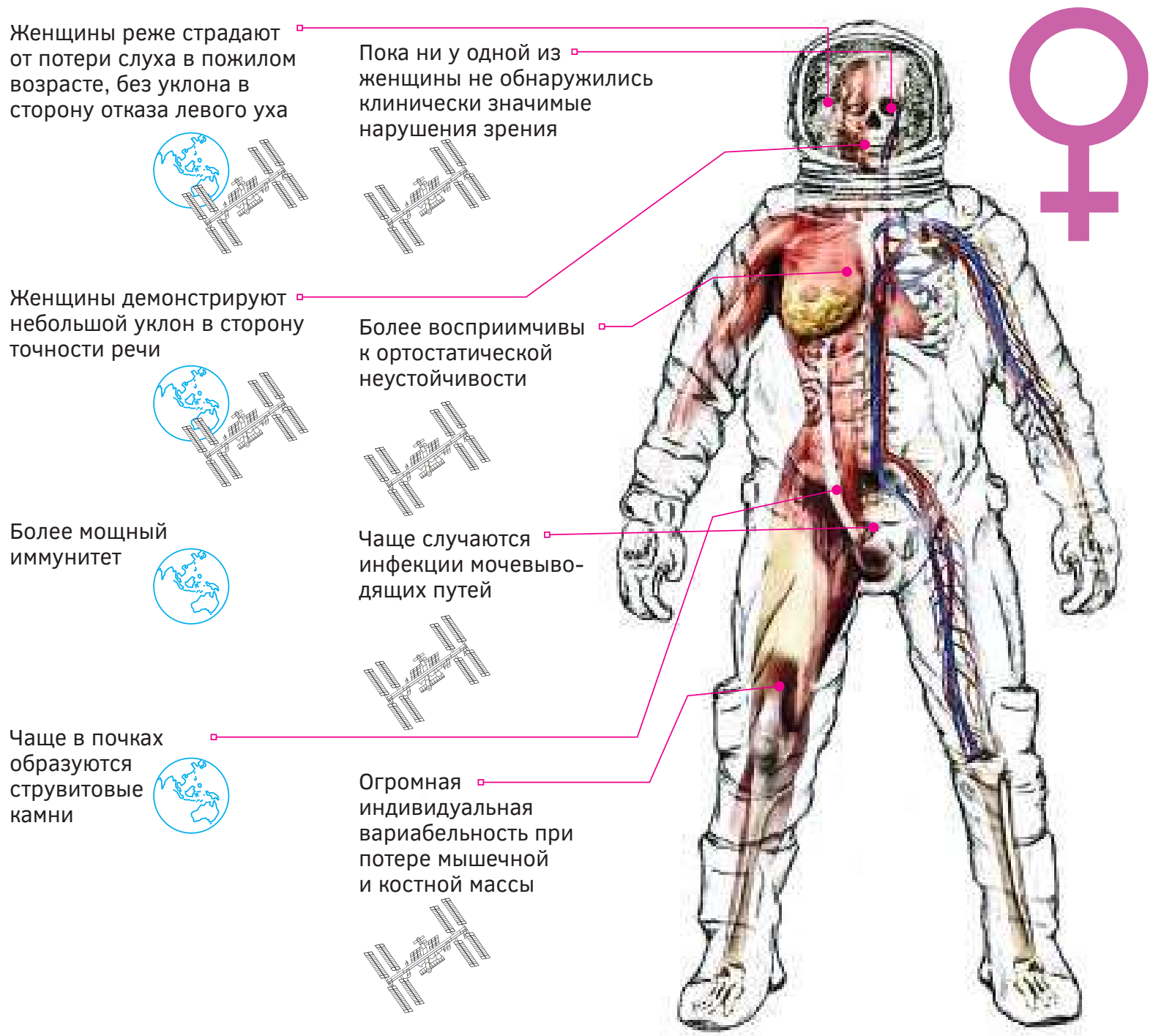

Сегодня установлен норматив годовой допустимой дозы облучения членов экипажа 500 мЗв. А еще есть общий лимит, накопленный в течение всех полетов: 1000 мЗв. При этом в атомной промышленности в России разрешенная нормативная годовая доза облучения не превышает 20 м3в. Ионизирующее излучение пагубно влияет на кроветворные и другие клетки иммунной системы.

У космонавта В.В. Васютина космическое излучение индуцировало рак предстательной железы, от которого он впоследствии скончался. Вместо расчетных 282 полет был прерван на 64-е сутки. «Полет был прерван по требованию врачей в связи с опасным болезненным состоянием В.В. Васютина вследствие урологической болезни. Генеральный конструк- тор академик В.П. ГлУШКО. 28.11.1985» (арх. № 266, л. 17-20) [23].

\section{ВЫВОДЫ}

«Локомотив космической экспансии уже запущен. Сегодня мы не можем перечислить всех перемен, которые принесет по-настоящему глобальное освоение космоса, так же, как нельзя было в точности спрогнозировать, насколько массовая компьютеризация изменит цивилизацию» [24].

На данный момент проект МКС полностью выполнил свою историческую миссию. Его век закончился. Эпоха начального освоения кос- 


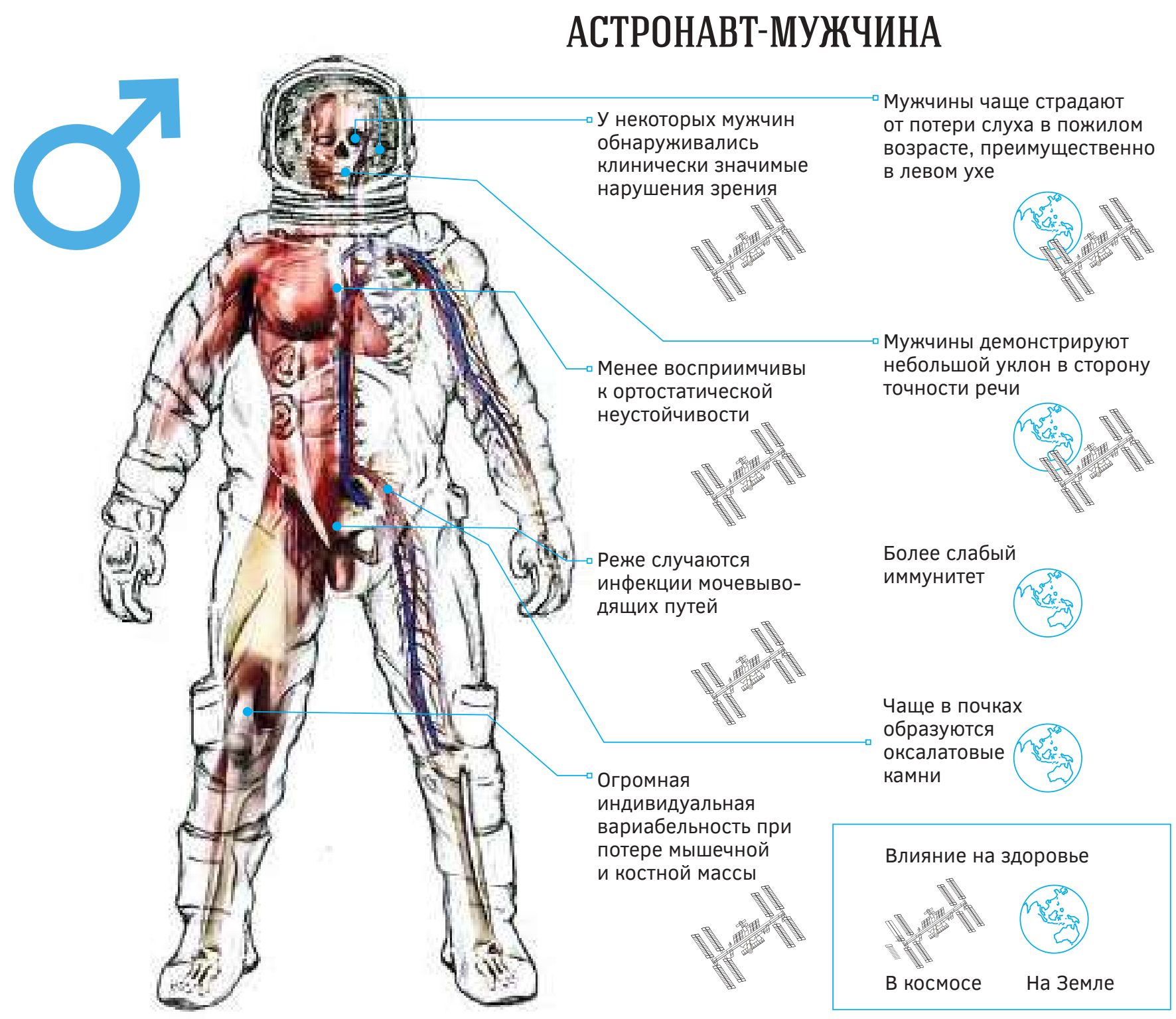

моса завершилась печальным мартирологом 217 космонавтов и кандидатов на полет в космос за 60 лет (1958-2018), что не может не заставить нас задуматься.

Создание гомеостатического ковчега - новое глобальное направление в освоении космоса. Оно является мощным локомотивом исторического прогресса цивилизации.

Идеи Илона Маска, Баса Лансдорпа и Денниса Тито о прямом заселении планет Солнечной системы вряд ли окажутся состоятельными с точки зрения современной теории космической медицины.

На сегодня нет никакой альтернативы международному проектированию и строительству всем миром Международного гомеостатиче-

ского ковчега (МГК) вместо отжившей свой век MKC. Наступает принципиально новая эпоха примата астрополитики над геополитикой.

Целевой задачей цивилизации становится тотальная индустриализация космоса, которая является прямым следствием индустриализации на Земле, начавшейся с первого плавания Колумба и открытия им Нового Света.

Вся экономика Земли постепенно будет подчинена этой новой задаче, что неизбежно приведет к полной реорганизации современного политического устройства общества на всей планете. Задачи конкретной геополитики каждой страны человечества объективно будут формироваться высшими надстрановыми задачами астрополитики цивилизации. 


\section{$\square$}

\section{Литература}

1. Дайсон Ф. Мечты о Земле и о небе. СПб: Питер, 2017. 368 с.

2. Игорь Ашурбейли рассказал о ближайших планах развития Асгардии [Электронный ресурс] // Персональный сайт И.Р. Ашурбейли. URL: https://www. ashurbeyli.ru/news/article/igor-ashurbeylirasskazal-o-blizhayshih-planah-raz-17092 (Дата обращения: 30.07.2018).

3. Федорова В.В. Космический ковчег и лунное поселение в ближайшие 15 лет // Воздушно-космическая сфера. 2018. № 1. С. 16-21.

4. Кроветворение и его регуляция [Электронный ресурc]. URL: https://studfiles. net/preview/5164192/page:5 (Дата обращения: 30.07.2018).

5. Valeri Polyakov [Электронный ресурс] // Википедия - свободная энциклопедия. URL: https://en.wikipedia.org/wiki/Valeri_ Polyakov (Дата обращения: 30.07.2018).

6. Вадим Иркутский. Сколько лететь с Земли до Марса - время и маршруты [Электронный ресурс] // Equity.today. Портал о мировых финансовых рынках. URL: https://equity.today/polet-na-mars.html (Дата обращения: 30.07.2018).

7. Кричевский С.В. Перспективы космической эры: сверхглобальные проекты и экологичные технологии // Воздушно-космическая сфера. 2018. № 1. С. 6-15.

8. Krichevsky S. Super Global Projects and Environmentally Friendly Technologies Used in Space Exploration: Realities and Prospects of the Space Age. Philosophy\&Cosmology, 2018, vol. 20, pp. 92-105.

9. Krichevsky S. Cosmic Humanity: Utopia, Realities, Prospects. Future Human Image. 2017. Vol. 7. Pp. 50-70.
10. Галимов Э. М. Замыслы и просчеты: фундаментальные космические исследования в России последнего двадцатилетия. Двадцать лет бесплодных усилий. М.: Едиториал УРCС, 2010. 304 c.

11. Космонавтика XXI века: попытка прогноза развития до 2001 года/Под. ред. Б.Е. Чертока. М.: РТСофт, 2010. 864 с.

12. Майборода А. О. Как создать лунную базу и орбитальную станцию на $80 \%$ дешевле // Воздушно-космическая сфера. 2018. № 1. С. 22-31.

13. Белоножко П.П. Космическая робототехника. Опыт и перспективы развития // Воздушно-космическая сфера. 2018. № 1. С. 84-93.

14. Белоножко П.П. Перспективные монтажно-сервисные роботизированные космические модули // Робототехника и техническая кибернетика. 2015. № 2 (7). C. 18-23.

15. Белоножко П.П. Космическая робототехника. Современное состояние, перспективные задачи, тенденции развития. Аналитический обзор // Наука и образование (МГТУ имени Н. Э. Баумана). Электронный журнал. 2016. № 12. С. 110-153.

DOI: $10.7463 / 1216.0853919$

16. Waddington, C. H. 1942. Canalization of development and the inheritance of acquired characters. Nature, no. 150, pp. 563-565.

17. Waddington, C.H. 1974. A Catastrophe Theory of Evolution. Annals of the New York Academy of Sciences, no. 231, pp. 32-42.

18. Циолковский К.э. Промышленное освоение космоса.М.: Машиностроение, 1989. 280 c.

19. Цандер Ф.А. Проблемы межпланетных полетов. М.: Наука, 1988. 232 с.

20. Eugenie Samuel. Space station radiation shields 'disappointing'. New Scientist, 23.10.2002
21. Мартиролог астронавтов, космонавтов и кандидатов [Электронный ресурс]//Космическая энциклопедия ASTROnote.URL:HYPERLINK"http://astronaut. $\mathrm{ru} /$ register/register04.htm?reload coolmenus"\/ "10"http://astronaut. ru/register/register04.htm?reload_ coolmenus\#10 (Дата обращения: 30.07.2018).

22. Виталий Головачев (2012). Отчего умирают космонавты // ParanormalNews. 10.06.2012. URL: http://paranormalnews.ru/blog/otchego_umirajut_ kosmonavty/2012-06-10-842 (Дата обращения: 30.07.2018).

23. Избранные работы академика В.П. Глушко. Сборник. Часть 3. Химки: ОАО «НПО Энергомаш имени академика В.П. Глушко», 2008. Письмо генерального конструктора НПО «Энергия» В.П. Глушко в ЦК КПСС. URL: http://astronaut.ru/crossroad/182.htm (Дата обращения: 30.07.2018).

24. Про локомотив космической экспансии [Электронный ресурс] // ЯндексДзен. Музей будущего. 11.05.2018. URL: https://zen. yandex.ru/media/muzey_budushego/prolokomotiv-kosmicheskoi-ekspansii-5af59 $6 f 57425 f 5 f c b c d e 7226$ (Дата обращения: 30.07.2018).

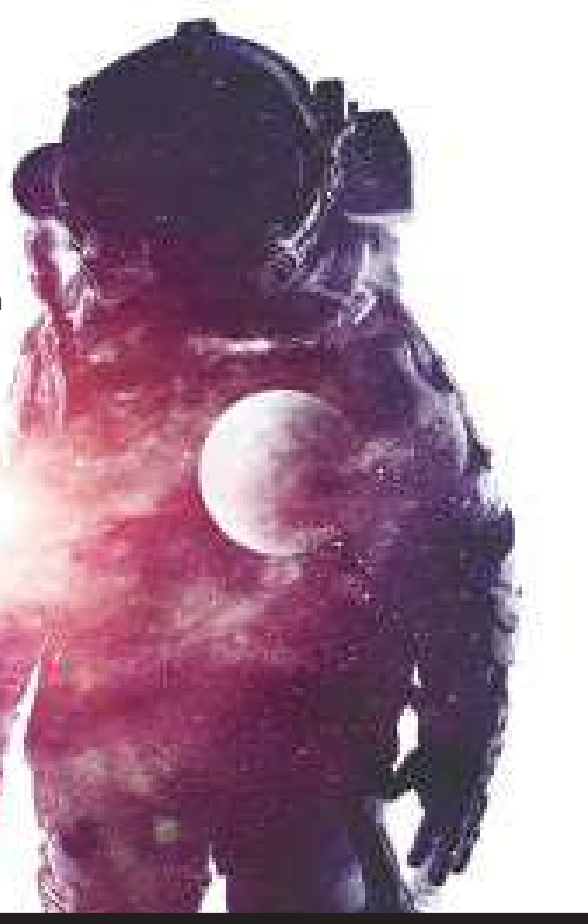




\section{[1]}

\section{References}

1. F. Dyson. Mechty o Zemle i o nebe. St. Petersburg, Piter, 2017. 368 p.

2. Igor' Ashurbeyli rasskazal o blizhayshikh planakh razvitiya Asgardii. Available at: https://www.ashurbeyli. ru/news/article/igor-ashurbeyli-rasskazalo-blizhayshih-planah-raz-17092 (Retrieval date: 30.07.2018).

3. Fedorova V.V. Kosmicheskiy kovcheg i lunnoye poseleniye $v$ blizhayshiye 15 let. Vozdushno-kosmicheskaya sfera, 2018, no. 1, pp. 16-21.

4. Krovotvoreniye i ego regulyatsiya. Available at: https://studfiles. net/preview/5164192/page:5 (Retrieval date: 30.07.2018).

5. Valeri Polyakov. Available at: https://en.wikipedia.org/wiki/Valeri_ Polyakov (Retrieval date: 30.07.2018).

6. Vadim Irkutskiy. Skol'ko letet' s Zemli do Marsa - vremya i marshruty. Equity.today. Portal o mirovykh finansovykh rynkakh. Available at: https://equity.today/polet-namars.html (Retrieval date: 30.07.2018).

7. Krichevsky S. V. Perspektivy kosmicheskoy ery: sverkhglobalniye proekty i ekologichniye tekhnologii. Vozdushno-kosmicheskaya sfera, 2018, no. 1, pp. 6-15.

8. Krichevsky S. Super Global Projects and Environmentally Friendly Technologies Used in Space Exploration: Realities and Prospects of the Space Age.Philosophy\&Cosmology, 2018, vol. 20, pp. 92-105.

9. Krichevsky S. Cosmic Humanity: Utopia, Realities, Prospects. Future Human Image, 2017, vol. 7, pp. 50-70.
10. Galimov E. M. Zamisly i proschety: Fundamentalniye kosmicheskiye issledovaniya $v$ Rossii poslednego dvadtsatiletiya. Dvadtsat let besplodnyh usiliy. Moscow, Editorial. URSS, 2010. 304 p.

11. Kosmonavtika XXI veka: popytka prognoza razvitiya do 2001 goda. Ed. by B.Ye.Chertok. Moscow, RTSoft, 2010. 864 p.

12. Mayboroda A. O. Kak sozdat lunnuyu bazu i orbitalnuyu stantsiyu na $80 \%$ deshevle. Vozdushno-kosmicheskaya sfera, 2018, no. 1, pp. 22-31.

13. Belonozhko P.P. Kosmicheskay a robototekhnika. Opyt i perspektivy razvitiya. Vozdushno-kosmicheskaya sfera, 2018, no. 1, pp. 84-93.

14. Belonozhko P.P. Perspektivniye montazhno-servisniye robotizirovanniye kosmicheskiye moduli. Robototekhnika i tekhnicheskaya kibernetika, 2015, no. 2 (7), pp. 18-23.

15. Belonozhko P. P. Kosmicheskaya robototekhnika. Sovremennoye sostoyaniye, perspektivniye zadachi, tendentsii razvitiya. Analiticheskiy obzor. Nauka i obrazovaniye (MSTU), Electronic journal, 2016 , no. 12 , pp. 110-153. DOI: 10.7463/1216.0853919

16. Waddington, C.H. 1942. Canalization of development and the inheritance of acquired characters. Nature, no. 150 (3811), pp. 563-565.

17. Waddington, C.H. 1974. A Catastrophe Theory of Evolution. Annals of the New York Academy of Sciences, no. 231, pp. 32-42.
18. Tsiolkovsky K.E. Promyshlenn oye osvoyeniye kosmosa. Moscow, Mashinostroyeniye, 1989. $280 \mathrm{p}$.

19. Tsander F.A. Problemy mezhplanetnyh poletov. Moscow, Nauka, 1988. 232 p.

20. Eugenie Samuel. Space station radiation shields 'disappointing'. New Scientist, 23.10.2002.

21. Martirolog astronavtov, kosmonavtov i kandidatov. Kosmicheskaya entsiklopediya ASTROnote. Available at: http://astronaut. ru/register/register04.htm?reload coolmenus\#10 (Retrieval date: 30.07.2018).

22. Vitaliy Golovachev. Otchego umirayut kosmonavty. ParanormalNews. 10.06.2012. Available at: http://paranormalnews.ru/blog/otchego_umirajut kosmonavty/2012-06-10-842 (Retrieval date: 30.07.2018).

23. Izbrannye raboty akademika V.P. Glushko. Sbornik. Chast' 3. Khimki: OAO «NPO Energomash imeni akademika V.P. Glushko», 2008. Pis'mo general'nogo konstruktora NPO «Energiya» V.P. Glushko v TSK KPSS. Available at: http://astronaut. ru/crossroad/182.htm (Retrieval date: 30.07.2018)

24. Pro lokomotiv kosmicheskoy ekspansii. YandeksDzen. Muzey budushchego. 11.05.2018. Available at: https://zen. yandex.ru/media/muzey_budushego/prolokomotiv-kosmicheskoi-ekspansii-5af5 96f57425f5fcbcde7226 (Retrieval date: 30.07.2018).

(C) Морозов С., 2018

История статьи:

Поступила в редакцию: 31.07.2018

Принята к публикации: 08.08.2018

Модератор: Гесс Л.А.

Конфликт интересов: отсутствует

Для цитирования:

Морозов С.Л. Гомеостатический ковчег как главное средство в стратегии освоения космоса.//Воздушно-космическая сфера. 2018. № 3(96). С. 28-37. 